\title{
OCEAN CRUSTAL DYNAMICS
}

by

\section{Donald M. Hussong}

Marine geologists and geophysicists from major ship-operating institutions in the U.S.A. have formulated a comprehensive research plan for the 1980's. Their specific recommendations, reviewed below, may have impact on marine scientific efforts around the world.

\section{Introduction}

The study of the oceanic crust has enjoyed wide attention, benefitting from the conceptual advances provided by the plate tectonic theory which revolutionized geologic thought in the past fifteen years. The theory provided a unified global model that explained and related many geological phenomena which previously appeared unrelated. It developed not from the study of land geology (the continents represent only the fragmentary remains of earlier episodes in the Earth's history), but from observations of the two-thirds of the Earth's surface lying beneath the oceans - where the fundamental processes of plate tectonics (sea floor spreading and subduction) are operating.

One would expect research in marine geology and geophysics to be in a period of intense activity, rapid progress, and expansion. Unfortunately this is not the case. In the U.S.A., for example, the science has entered a period of relative stagnation because funding for basic oceanographic research by scientists in academic institutions has not kept up with inflation. In the face of dwindling fuel and other natural resources, when efforts could be made to identify all areas of long-range economic interest beneath the oceans, the level of appropriate marine studies is being reduced.

This situation prompted the Joint Oceanographic Institutions, Inc. (JOI), a non-profit corporation established and governed by ten major U.S. oceanographic research institutions, to commission a panel of active researchers in marine geology and geophysics to consider the general goals of their scientific field in the 1980's. The panel, called Ocean Crustal Dynamics Planning Committee (OCDPC), then proceeded to identify what initiatives are required to provide the funding, facilities, and coordination necessary to reach these scientific goals.

To obtain broad input to their scientific planning, the OCDPC convened in 1979 a series of eight workshops during which experts from academia, industry, and government research units met and debated portions of the research effort in detail. Their reports, representing the cumulative efforts of over 100 active researchers, have now been distilled into an Ocean Crustal Dynamics (OCD) program plan which has been circulated to the U.S. marine research community for review.

\section{OCD Scientific Goals}

The committee was concerned with general questions bearing on the oceanic crust. Specifically: (1) What is the composition and mineralogical make-up of the ocean crust? How does this composition vary in space and time? (2) What processes are involved in the formation and evolution of oceanic crust? (3) What is the nature and origin of the boundary between the lithosphere (plate) and asthenosphere (beneath the plate)? (4) What is the driving mechanism of plate tectonics? (5) What type of plate interactions occur at active (convergent) boundaries? (6) What are the nature and evolutionary development of rifted (passive) ocean-continent boundaries? (7) What is the relationship between plate tectonics and the geochemical and thermal balance of the lithosphere?

These are all fundamental scientific problems that are now being investigated by scientists worldwide. The committee was concerned, therefore, that progress toward solving these problems might be curtailed because of the lack of required resources and tools to work on them in an efficient manner. To illustrate, one might focus on the topic of plate interaction at convergent margins (noted as item 5 above).

Study of the active margins is essential for several reasons: (i) $90 \%$ of the world's large earthquakes take place at active continental margins such as almost the entire rim of the Pacific Ocean; (ii) volcanic eruptions along active margins are generally the most explosive and dangerous on Earth; (iii) geologic structures interpreted as the remnants of active margins contain a large portion of the world's mineral wealth as known to us now.

The occurrence of such mineral deposits is directly linked to the complex geological processes taking place in the formation and evolution of active margins, including volcanism. The shallow seas in active margin areas are gaining attention too as some of the last, relatively unexplored areas having reasonable petroleum potential. Programs directed toward understanding these geologic processes and environments should also lead toward the development of more sophisticated methods of prospecting and the discovery of new metallic minerals, petroleum, and other deposits and resources which our society needs for survival.

In spite of their significance and past research, active margins are still poorly understood by earth scientists. The steep slopes and complex structure of convergent (active) margin regions make them difficult targets for geophysical exploration. Although early data obtained from a few seismic studies were not completely conclusive, most interpretations suggested that the overriding trench wall was composed of a chaotic mass of compressed and uplifted sea floor sediments and rocks (upper section in Fig. 1). Such a geologic structure offers little potential as a region for petroleum exploration.

This initial interpretation of the geology of a few Pacific margin regions was subsequently extrapolated to essentially all such regions, with the result that most of the rim of the deep Pacific Ocean was thought to have negligible potential for petroleum exploration.

Starting in 1977, however, detailed surveys followed by deep drilling using the GLOMAR CHALLENGER showed that the landward trench walls near Japan, the Marianas, and probably Central America, are entirely different from the almost universally applied geologic model suggested above. They are apparently composed largely of subsided continental (or island arc) sediments and crust (lower section of Fig. 1). If these recent interpretations are verified, it may be that these vast areas of thick sediment around the Pacific and other oceans were prematurely dismissed as having no petroleum potential.

It has been graphically illustrated in recent active margin studies that the crucial, and of ten economically significant, finer details of plate tectonics are not being adequately resolved. We do not fully know the answers to the following questions, for instance.

How severe and geographically extensive is the deformation caused by plate collision and subduction? 


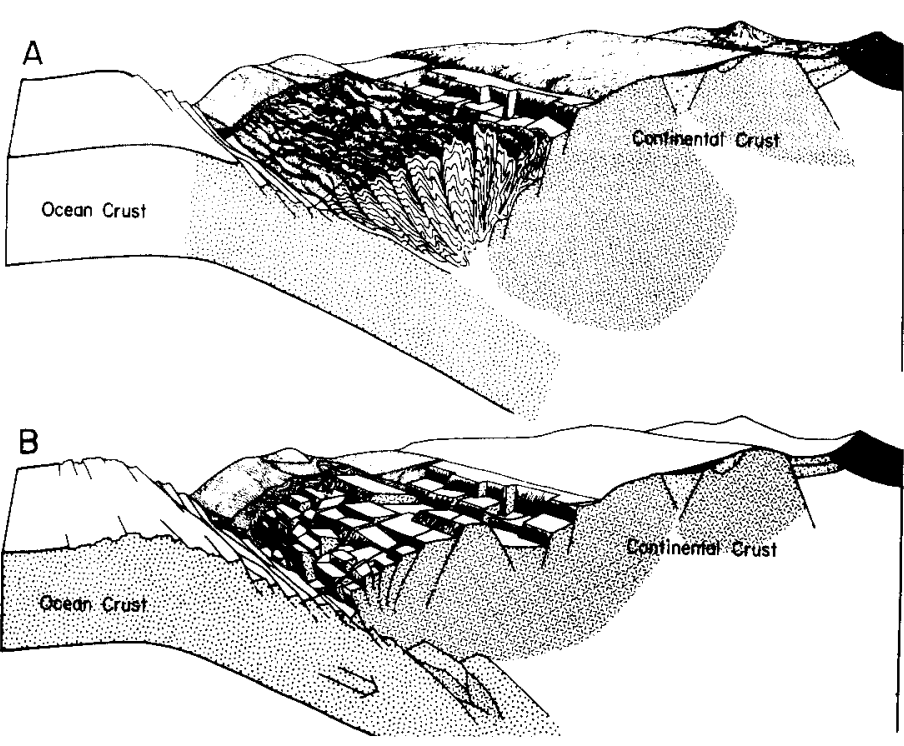

Figure 1. Contrasting models of active convergent margin structure. Section $A$ on top is dominated by a large accreted prism of largely oceanic sediments and rocks that will uplift with time. Section $B$ on the bottom is an example of tectonic erosion where the fore-arc is composed of continental rock that is progressively fractured and subducted, resulting in subsidence with time. (Drawings courtesy Bill Coulbourn, Scripps Institution of Oceanography)

- What is the stress distribution in convergent regions, including back-arc areas? Can temporal changes in the stress/strain field be detected and ultimately predicted?

- Do the variety of observed structures of island arcs correspond with different conditions of stress? How are the orogenic forces in oceanic/continental convergence regions transmitted from the collision point to the mountains on the overriding plate?

- What is the temperature distribution on the convergent zone? How is this related to convergent margin geometry? How important, how deep, and how extensive are the highfriction regions that supposedly heat up the upper surface of the subductive slab to produce magmas?

- How do physical properties of sediments in fore-arc areas vary? What is the geologic history of the sediments? How do soft sediments evolve into highly deformed, metamorphically complex orogenic zones? What is the fate of subducted oceanic sediments?

- What are the physical properties (for example - size, deformation, temperature), and mineralogical and compositional make-up of the descending slab?

- When and why do we have continental accretion as opposed to tectonic erosion of the subducting slab? What is the mechanism causing the recently discovered subsidence of many fore-arc regions?

An extensive series of coordinated experiments is needed to test these questions, starting with acquisition of better reference data. For example, we now know the water depth to an accuracy of better than $\pm 100 \mathrm{~m}$ in less than $0.1 \%$ of the oceanic trench areas. Yet acquisition of accurate topographic data, taken for granted by land geologists, requires very expensive and highly technical equipment in the oceans.

\section{Proposed Experiments}

With adequate background data, one could conduct some sophisticated but necessary experiments such as the following:

1. Systematic studies of the temporal relationship and interaction of various dynamic components of the subduction zone, including seismicity, volcanism, sediment characteristics and distribution, ocean plate deformation and vertical motion of the colliding plates;
2. Long-term seismicity measurements, both on-shore and off-shore, with ocean bottom seismometers or ocean bottom observatories, to better determine the tectonic and kinematic patterns of the subduction zone;

3. In situ stress measurements;

4. Long- and short-term measurements of horizontal and vertical displacement of the ocean bottom;

5. Detailed examination, using high-resolution data acquisition techniques, of the landward wall of the trenches;

6. Detailed mapping combined with mineralogical, isotopic, and chemical analyses of volcanic products and residual mantle rocks in those regions which have been uplifted and exposed.

The common thread running through all OCD discussions has been the need for better coordination of various marine and continental earth science studies, and the need for better data in the 1980's.

\section{Program Requirements}

Marine geological and geophysical data gathered over the past twenty years have proven that the broad conceptual (plate tectonic) models of genesis, aging, deformation, and destruction of oceanic crust are correct. However, the development and testing of more refined models of oceanic crustal structure and tectonics, including the dynamic kinematic parameters which the OCDPC and OCD workshops identified as essential, require more precise data. While in some cases the tools and techniques to acquire these data have yet to be developed, in others they already exist but are too expensive for use by university research laboratories.

The OCDPC did not discuss the present or proposed future deep ocean scientific drilling programs because these endeavours are receiving considerable attention by many other groups. Committee recommendations range from plans for specific experiments using existing tools and techniques to less precisely defined expressions of the need for new technologies in order to make particular kinds of observations, and for improved communication between different groups of earth scientists. Highlights from each of the workshop reports follow.

\section{High-Resolution Bathymetry}

Accurate and detailed topographic base maps are the first requirement of geological studies on land. The technology is such that detailed topography of the oceans is now possible and should be utilized. Specific recommendations included:

- immediate acquistion of two multi-beam bathymetric charting systems for installation on academic research ships, with adequate support to operate the systems, and subsequent acquisition and installation of other multibeam systems on four additional major deep-ocean U.S. oceanographic vessels during 1980-1990;

- increased support for deep-towed geophysical profiling systems in order to increase their availability to the scientific community; and

- support for the use of GLORIA, a British long-range sidescan sonar system.

\section{Mobile Seismic Arrays}

Marine multichannel seismic (MSC) systems were developed during the 1960's for oil and gas exploration and their capabilities have evolved rapidly. Continuing improvements in digital recording, shooting techniques, and especially computer processing techniques have led to vast amounts of new subsurface information, particularly on the continental margins. A substantial effort should be devoted to the development of appropriate MCS technology - theory, hardware and processing techniques, including:

- analysis of existing MCS data to better understand $Q$ in various sediment and rock types as well as absorption and reflectivity characteristics of different types of interfaces; - support of experimental and analytical work to better understand and suppress source-generated noise from 
multiple reflections and scattered noise from chaotic sections such as convergent margins;

- development of deep-towed receivers and high-power, deep-towed repetitive sources;

- further development of direct inversion techniques to determine physical properties of subsurface rock, including downhole and laboratory measurements; and

- development of the capability to utilize shear waves in seismic exploration.

Preparations for the Large Aperture Seismic Array (LASE) experiment, to be conducted off the east coast of the U.S.A., are now underway. In this experiment, three MCS vessels will steam in a close line to simulate a very long $(>10 \mathrm{~km})$ hydrophone receiving array (Fig. 2) using three conventional

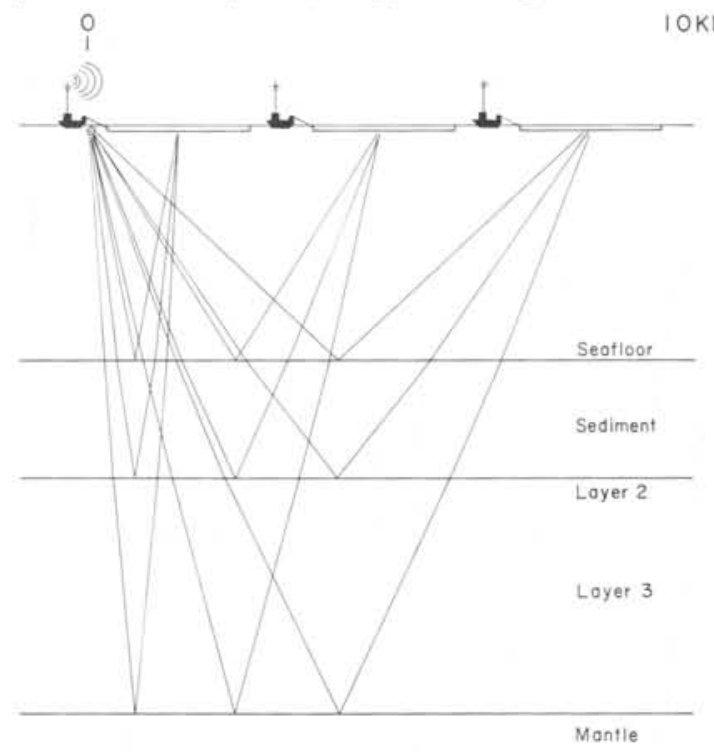

Figure 2. A method of continuously recording wide-aperture seismic data along a profile line. Three ships, each with a 3 $\mathrm{km}$ receiving array, steam along a track line. The lead ship fires a repetitive seismic source. Signals follow various paths (through hypothetically simple layers) as shown and are recorded by all three vessels, simulating a very long mobile array. (Figure courtesy P. Buhl, J. Diebold, and P. Stoffa; Lamont-Doherty Geological Observatory)

hydrophone arrays. The long shot-to-receiver geometry permits collection of continuous wide-angle reflection and refraction seismic arrivals that will allow accurate determination of the velocity of deep crustal layers (Fig. 3).

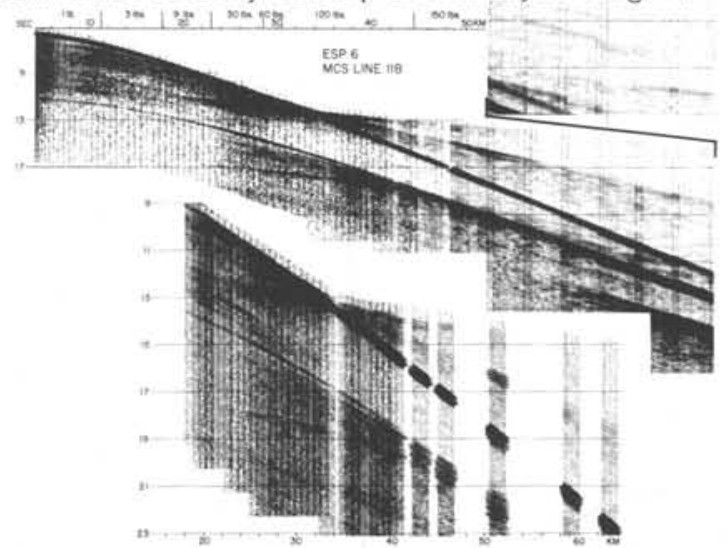

Figure 3. Data from a wide aperture seismic experiment, 2 to $100 \mathrm{~km}$ source-receiver distance, from the Caribbean Sea. By using a long multi-channel receiving array we can record data at many source-receiver offsets using only a few explosive charges. The upper record shows all data recorded; the lower record is a detail at an expanded scale. To avoid clutter only one-third of the data is shown. (Figure courtesy P. Buhl, J. Diebold, and P. Stoffa, Lamont-Doherty Geological Observatory)
Although some of the most exciting new results in marine geology have come from bottom observations, no new technologies involving such observations and sampling have been developed in the last ten years. Recent technological capabilities with remote-controlled submersibles and television systems could make such observations more efficient and less hazardous to human life.

Other related problems exist where little effort is being expended because of financial and technological limitations. One such area is the direct measurement of crustal strain related to tectonic processes using borehole (volumetric strain) and geodetic (triangulation) methods. High-resolution acoustic techniques for studying subsurface geologic structures in deep water are essential. Observations at the sea surface provide a very blurred image of the subsurface because of backscattering due to irregular topography. Observations near the sea floor with deep-towed arrays would greatly alleviate this problem by moving backscattered energy into time and velocity windows that allow for signal enhancement.

Obviously, most geophysical or geological profiling now done on the sea surface should be done near the sea floor in order to obtain adequate high resolution data. Specific requirements include:

- development and deployment of deep-towed arrays for seismic reflection and refraction profiling;

- development and operation of systems to measure strain in different areas of the ocean floor;

- adequate support to build and operate at least five 20element OBS systems for use in long-term (greater than six months) seismicity studies;

- development of the capability to obtain oriented samples of igneous rock from within $10 \mathrm{~m}$ of the rock-water interface using drills lowered from conventional research vessels;

- development of unmanned cable-controlled vehicles for work in water depths greater than $6 \mathrm{~km}$;

- improved acoustic imaging of the sea floor, including experiments with acoustic holography; and

- development and operation of deep-towed vector magnetometer systems, a CTD with improved resolution of temperature and salinity (and including a nephelometer), a portable mass spectrometer for shipboard measurement of $\mathrm{He}^{3}$; and an in situ Mn probe.

\section{Facilities for Sample Analysis}

Many problems of ocean crustal dynamics will be solved only by the careful study of actual rock samples obtained by conventional dredging (using acoustic navigation), submersibles and deep drilling. Specific regions considered for detailed study include various types of ocean ridge spreading centers, fracture zones, back-arc basins, older sea floor, and areas of particular geochemical interest (such as regions with hydrothermal activity). The proper analysis of these samples requires improved shipboard and onshore laboratory facilities. Specific recommendations of this workshop included:

- upgrading, replacing, automating and expanding existing laboratories to conduct high-quality, comprehensive analytical work;

- development of an integrated analytical approach to the study of oceanic rock samples (mineralogical, major-element, trace-element, stable and radiogenic-isotope analyses and experimental studies should be made on the same samples); - standardization of sample preparation procedures and inter-laboratory calibration of sample anaylses; and

- establishment of a proper rock curation facility with easy access to published analytical data.

\section{Drill Hole Utilization}

This OCD workshop strongly endorsed the continuation of deep ocean scientific drilling during the next decade, and suggested evaluation of other drilling techniques, to comple- 
ment the GLOMAR CHALLENGER or GLOMAR EXPLORER program. It also recommended better utilization of scientific drill holes. Recommendations included:

- evaluation of drilling on islands, atolls, and dry continental margins;

- evaluation of the possibility of conversion of a $65-100 \mathrm{~m}$ commercial supply boat for deep piston coring;

- establishment within the organization managing the U.S. deep ocean scientific drilling effort of an inhouse logging capability, including hardware and personnel, and an organization to coordinate downhole experiments;

- funding to routinely insert casing down to basement (or to competent rock) in order to ensure that certain drill holes may be re-entered for future use; and

- development of the capability to place sensors in existing drill holes using a conventional research ship (not a drilling ship).

Deep ocean hydraulic piston coring is now being routinely carried out by the GLOMAR CHALLENGER. The ability to remove essentially undisturbed cores (Fig. 4) in soft sediments (typically the upper $200 \mathrm{~m}$ of ocean sediments) provides stratigraphers with the high resolution needed for effective study. This is the kind of technological breakthrough that is needed for many of the scientific problems identified by the OCDPC.

The hydraulic piston core used on the GLOMAR CHALLENGER (Fig. 5) is a time-consuming tool for a large and costly drillship normally used as a rotary drilling platform. Obviously, this tool should be used on a smaller, less expensive ship if possible.

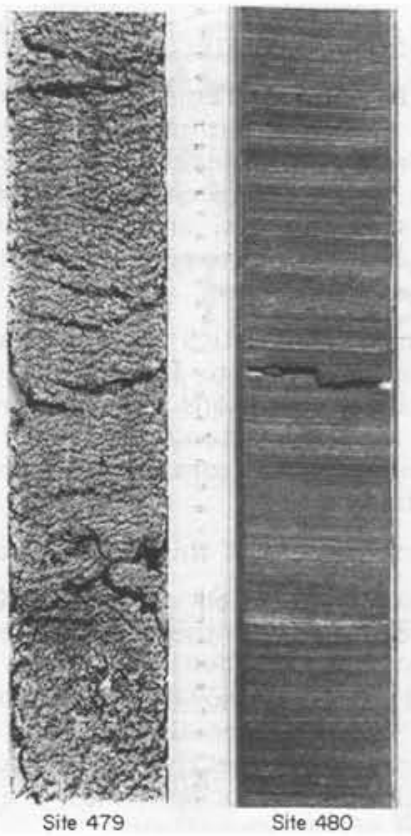

Figure 4. Two cores of the same sequence of Quaternary sediments recovered by the GLOMAR CHALLENGER Leg 64 in the Guaymas Basin, Gulf of California. Core 12, Site 479 was taken using conventional rotary drilling technique and is highly disturbed. Core 20, Site 480 was taken using the Hydraulic Piston Corer recently developed at the Deep Sea Drilling Project by M. Storms and S. Serocki. The piston corer provides an essentially undisturbed sediment sample.

OPERATIONAL SEQUENCES - DSDP HYDRAULIC PISTON CORER

1

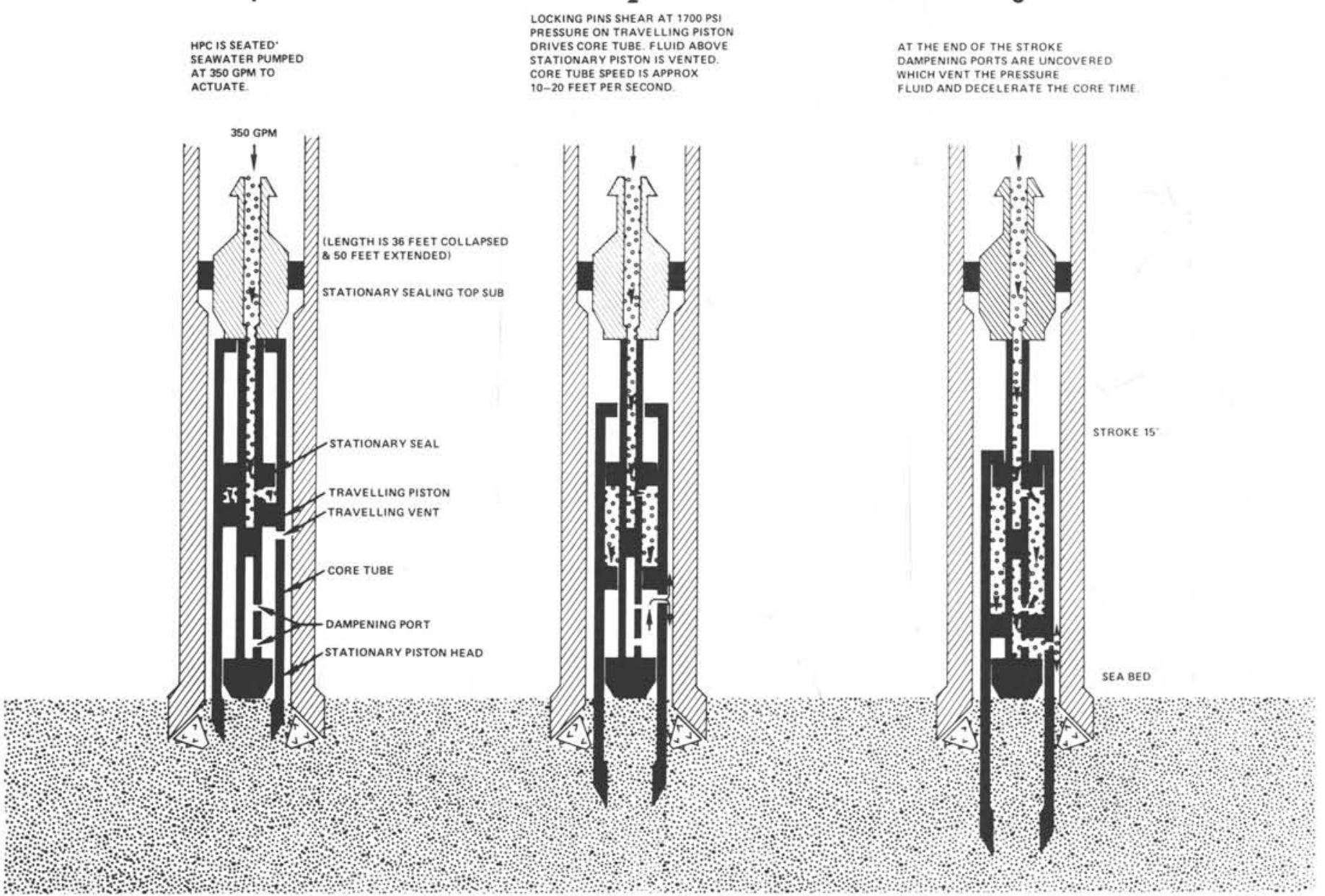

Figure 5. Operation of the DSDP hydraulic piston corer. 
jeothermal, Geomagnetic, Electromagnetic Experiments

Jceanic heat flow measurements provide powerful con;traints on the models of lithospheric plate generation and zooling, hydrothermal circulation, subduction tectonics, and the maturation of hydrocarbons. Electromagnetic studies rovide larger scale models, and in the ocean basins have zreat potential for determining the thermal structure of the ithosphere and asthenosphere.

Advances in marine magnetics instrumentation would allow study of the source region for the sea floor spreading magnetic anomalies, conditions of emplacement of the magnetic material, and the tectonic disruption of the magnetic material as it moves away from the ridge crest in response to sea floor spreading.

Specific recommendations of this workshop are:

- development and operation of a continuous temperature conductivity profiler and a thermal blanket-type heat flow meter;

- institution of programs for geothermal studies on ridge axes and ridge flanks (especially a study of the transition zone between areas of convective and conductive heat transport) and on active passive ocean margins, as well as electromagnetic studies of the ocean floor;

- development and operation of an intermediate level, rapid magnetic vector gradiometer and a borehole magnetometer; and

- initiation of a program of detailed aeromagnetic surveys of selected areas of the ocean floor.

\section{Long-term Ocean Botton Observatories}

The development of long-term ocean bottom observatories (LOBO's), a multi-purpose instrument platform capable of making a variety of ocean bottom measurements and serving many disciplines, is the most science-effective and costeffective approach to many problems of routine sea floor observation. The construction, deployment, and operation of LOBO systems are feasible with existing technologies or with technologies currently in advanced stages of development.

This panel recommended institution of a ten-year program aimed at development, deployment and operation of a 10 element LOBO network.

\section{Ocean-Land Transitions}

Fundamental and exciting scientific problems in the transition zone between oceans and continents include: (1) initial conditions of plate break-up; (2) vertical tectonics of margins and influence on margin sedimentation processes and facies; (3) continuous as opposed to discontinuous subduction of convergent margins; and (4) evolution of mantle and crust beneath oceans and continents. Natural and artificial barriers which arise when working across shorelines must be eliminated before basic scientific questions related to the origin and evolution of continental margins can be attacked. More open communication between land and marine geologists and geophysicists is essential. This workshop concluded that the most efficient approach to studying oceanland transitions will be to focus intensive effort on selected transects across continental margins. In discussing a U.S. funded effort, appropriate transects in the U.S.A. were emphasized (Fig. 6). These detailed geological and geophysical studies of continental and marine transects could culminate in deep scientific drilling.

\section{General recommendations were:}

- initiation of a comprehensive compilation of ocean and land geology at appropriate scales and map projections as the essential first step in the study of ocean-land transitions; - a follow-up integrated effort to select the most representative ocean-land transitions for study of the processes controlling formation and evolution of our continental margins.

\section{Conclusion}

The total array of technology development and scientific experiments envisioned by the OCDPC for implementation during this decade is large and expensive. It does not, however, require as large an increase in funding as might be anticipated. Much of the work will be carried out, and much of the money is already available, regardless of OCD. The primary goal of OCD is to help obtain the required increment of commitment, coordination, and funding to maximize the progress of marine geological and geophysical research in the 1980's.

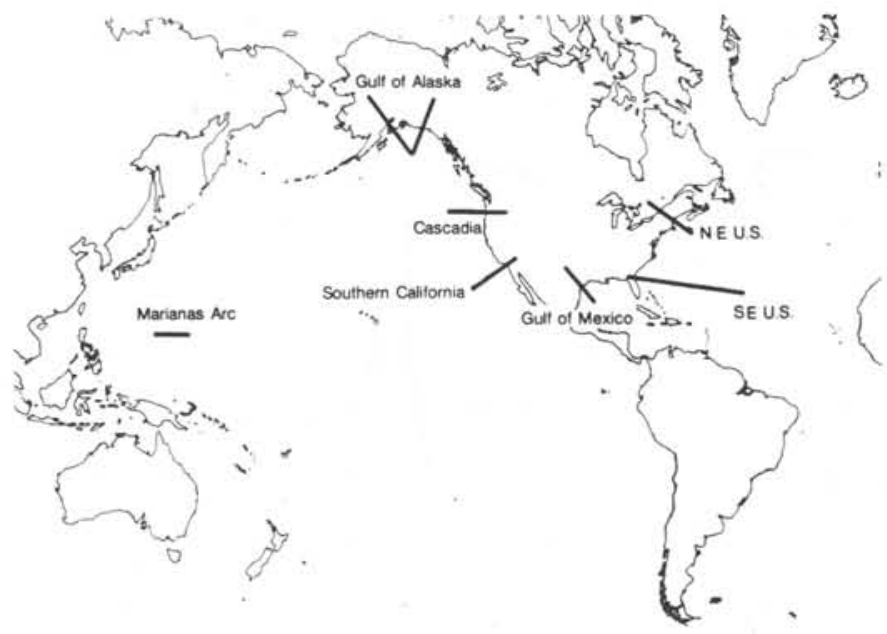

Figure 6. Preliminary location of U.S. Ocean Crustal Dynamics Scientific transects.

\section{Members of the Ocean Crustal Dynamics Planning Committee:}

D. M. Hussong (Chairman), Hawaii Institute of Geophysics; J. Ewing, Woods Hole Oceanographic Institution; C. Harrison, University of Miami; T.W.C. Hilde, Texas A\&M University; T.H. Jordon, Scripps Institution of Oceanography; B.T.R. Lewis, University of Washington; K. Scheidegger, Oregon State University; J.G. Schilling, University of Rhode Island; M. Talwani, Lamont-Doherty Geological Observatory.

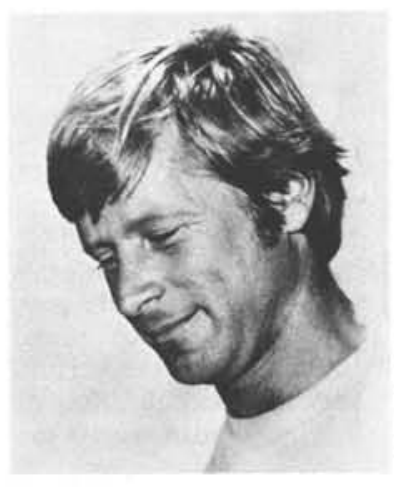

ABOUT THE AUTHOR: Associate Geophysicist at the Hawaii Institute of Geophysics, University of Hawaii, Donald Hussong's research interests are marine geophysics, seismology and tectonic evolution of plate margins. His most recent work has concentrated on the Peru-Chile Trench, Middle America Trench, Mariana Island Arc and the Oceanographer Fracture Zone. Dr. Hussong is Chairman of the Ocean Crustal Dynamics Planning Committee. 